\title{
SPOUSAL VIOLENCE IN THE ERA OF COVID-19 LOCKDOWN: THE IMPLICATION OF SOCIOECONOMIC DISTRESS AND CONTEXTUAL FACTORS
}

\author{
Rotimi Oguntayo $^{1 *}$, Abiola O. Popoola ${ }^{1}$, 'Remi S. Opayemi ${ }^{2}$, Omolara R. Faworaja ${ }^{1}$ \& Abayomi \\ O. Olaseni ${ }^{1}$ \\ ${ }^{1}$ Department of Psychology, University of Ilorin, Ilorin, Nigeria \\ ${ }^{2}$ Department of Psychology, University of Winnipeg, Manitoba, Canada \\ *Corresponding author's email: rotimijoguntayo@ gmail.com
}

\begin{abstract}
Globally, there are overwhelming evidence on the increasing spate of domestic violence among couples during the coronavirus lockdown. However, there are limited empirical studies that have explored the role of socioeconomic distress on spousal violence occurrence during the enforced lockdown in Nigeria. This study investigated how contextual, socio-demographic factors, economic distress interplay with spousal violence (SV) during enforced lockdown due to COVID-19. A web-based cross-sectional study utilizing snowballing sampling technique was adopted. Participants were recruited via social media platform, Facebook and WhatsApp using google form from March 3 to April 4, 2020. 356 participants (141 males and 215 females) responded to questionnaire containing socioeconomic, demographic information and Composite Abuse Scale (CAS); which was used to assess spousal violence. Result showed that living conditions of couples, income status and job status had significant influence on SV. However, gender, religion affiliation, type of family, and spouse's tribal affiliation had no significant influence on SV. The study concluded that contextual factors and socioeconomic distress exert significant implications on spousal violence. It was recommended that government at all levels should be objective in the distribution of palliative measures to combat socio-contextual and economic distress among residents to achieve a spousal violence free society among Nigerians during and in future pandemic lockdown.
\end{abstract}

Keywords: COVID-19 Lockdown, Economic distress, Living condition, Spousal violence.

JEL Classification: J12

\section{Introduction}

Globally, nations have been battling with the spread of the novel coronavirus disease of 2019 (COVID-19) and has widely caused mortality rate of over 763,390 thousand nationwide (Worldometer, 2020). One of the measures or the most significant measure to contain the COVID-19 is avoidance of social interaction especially at worship centers, workplace and restriction of movement among residents, thereby culminating into an enforced locked down as declared by the concerned authorities (World Health Organisation, 2020; Federal Government of Nigeria, 2020).

The enforced lockdown has badly affected so many families, especially those within the middle and low socioeconomic status (SES). The SES of residents in Nigeria were seriously affected because, many within the active age were unable to go out to sort for their basic needs, some working in private organizations were placed on half-salary and some weren't paid at all (United Nations Nigeria (UNN), 2020). UNN further explained that, unlike many developed nations, the government of Nigeria was not responsive to the outcry of the masses as regards moderating the effect of COVID-19 by issuing adequate palliatives to the seriously affected masses. These might have caused some concerns raised on sudden surge in spousal violence among residents in Nigeria (Lagos State Domestic and Sexual Violence Response Team reported (DSVRT, 2020). Furthermore, there are limited empirical studies that establish the possible factors escalating this psychosocial problem. Meanwhile a recent study that was conducted in Lagos (the epicenter of COVID-19 emergency in Nigeria) revealed that, the 
unprecedented stress of the coronavirus pandemic predisposed some certain numbers of spouse to disputing homes or domestic violence (Oguntayo et al., 2020). According to the Centers for Disease Control and Prevention (n.d), 1 in 3-female and 1 in 4-male spouse in the United States have experienced violence from their spouse or are at the risks of being victims. The advent of coronavirus outbreak has surged this psychosocial challenge in Nigeria (United Nations Women, 2020).

Numerous studies have contributed to the awareness of SV in the past, however, there is a dearth of literature focusing SV amid coronavirus pandemic. News in Nigeria has revealed that there is sudden increase in the rate of SV across the nation in March 2020 (Olatunji, 2020). The pandemic situation in Nigeria might have contributed to this global trend of increased SV. For instance, SV was revealed to have significantly increase in number immediately after the lockdown began in Nigeria and the most affected states, were; Lagos, Abuja, FCT (Federal Capital Territory) and Ogun States which were the first three states to be locked down in Nigeria (DSVRT, 2020; United Nations Women, 2020). In addition, DSVRT (2020) found that, there were three folds surge in the rate of telephone calls received on SV in the month of March to April 2020. Other states in Nigeria that later implemented the same policy of lockdown might probably witness similar challenges, however no studies have revealed this yet. SV is an abuse that is committed by intimate partners which is manifested through emotional abuse, physical abuse, sexual abuse, economic abuse, and acts of omission (United Nations International Children Emergency Fund (UNICEF, 2000). It could inferred that, SV is the combination of both physical and forcible behaviours in which in-turn culminates into manipulation and domination of one's spouse. The emotional and behavioural characteristics of SV include; partner beating, battering, hitting, relationship violence, victimization, bullying and abuses of all types (UNICEF, 2000).

According to Kishor (2012), women are the top victims of SV and, more than 35\% of women worldwide were purported to have experienced either SV or specifically the partner sexual violence in their lifetime (World Health Organisation (WHO, 2014). According to a survey research conducted by WHO in 2017, victims of SV witnessed some trauma related injuries such as; sexual or psychological harm, harmful controlling behaviours, and chronic health conditions, body pain, pelvic pain, ulcer and sudden death (WHO, 2017). Violence against spouse has a lot of costs to present and future generations of children (United States Agency for International Development (USAID, 2014). Recently, it has been reported that more cases of violence against women are on increase side daily (Oguntayo et al. 2020), while, the cases of male partners being the victim of SV are scarcely reported (Oguntayo et al., 2018). Oguntayo et al further found that, some cultural beliefs and values hinder males from reporting SV to authority, instead they conceal it to show that they are manly enough to control their family. Previous studies from the Ebola outbreak in country like Sierra Leone revealed that the economic problem in female-related patterns of employment, school closures, and loss of personal business could lead to serious family challenges (United Nations Fund for Population Activities (UNFPA, 2020). In addition, hardship caused by COVID-19 pandemic has left many couples economically drained which may have culminated into aggression and frustration (UNN, 2020).

The media has reported and still reporting the devastating toll that coronavirus outbreak is taking each day, enumerating the number of cases of COVID-19, those hospitalized and those that have died (Worldometer, 2020). These are glaring pains but there are other pains and injuries that COVID-19 pandemic has caused the society, such injuries includes some related factors that predispose women and men to some intimate partner violence (Baker-Tingey, 2020). The Centers for Disease Control and Prevention (n.d) revealed that up to $41 \%$ of women and $14 \%$ of men are experiencing spousal violence during the COVID-19 outbreak and more of its survivors may experience some form of sexual, economic and physical injury that are associated with spousal violence. This phenomenon is not attended to adequately and timely whereas it could worsen the economic strength of a country, health condition and cause deformation of people, broken home, displacement of children and death of the victims (DSVRT, 2020). Nigeria is ranks on top among nations in the world that have the cases of women being murdered by a recurrent or past intimate partner abuse (DSVRT, 2020). 
According to DSVRT, as people and families' movement were restricted during the COVID-19 pandemic, so also more reports of SV increase. Consequently, the home challenges like divorce may also increase after the pandemic in some areas in Nigeria. One may be curious to know the perpetuating factors for this surge. Socioeconomic challenges such as; loss of job, financial constraint, and poverty might have trigger SV. Meanwhile it has been suggested that majority of Nigeria residents were helpless and economically distressed thereby causing decline in families coping skills (Olatunji, 2020). The sides effects of SV include; acute sicknesses, heart or chest pains, the digestive problem, miscarriage, low reproductive ability and nerves damages; orthopedic problem, distress, and muscles dysfunctions (Baker-Tingey, 2020; Oguntayo et al., 2018). The spate of SV may have decreased drastically should authorities concern, such as government or Non-Governmental Organizations (NGOs) situates call toll free lines on spousal violence across the nation to discourage potential perpetrators.

During the COVID-19 lockdown, seeking experts' help or moving away from the distressing zone as well as reporting at police stations was even more challenging as there was no movement allowed, unless it on physical health issue (Olatunji, 2020). Victims were exposed to more distressing situation than before and more difficult time utilising safe environment or spaces as well as depriving of resources such as; welfare services, community services and social resource centers, and courts (Bettinger-Lopez \& Bro, 2020). Furthermore, going to workplace and taking children to school, most time create opportunity to share with others about their condition, seek experts' help or utilise a break from the spouse that abuses. The closure of schools, non-essential services and businesses, made the victims to be deprived of these opportunities. Meanwhile study like Oguntayo (2016), has shown that socioeconomic factors could predict spousal violence.

According to Gjertson, (2011), females' economic status is related to spousal violence in three elementary manners: First, even when SV happens across socioeconomic strata, poorer women has tendency to endure or survive it more than affluent women. Second, females who are not financially buoyant than their abusers are less likely to quit but have tendency to resolve with the abusive spouse. Moreover, the degree of females' financial dependence on an abusive spouse is related with the gravity of the violence the women will suffer. Third, economic abuse on its own is a form of spousal violence; violent partners may behave in manners that could deteriorate the women economically and diminish the capability to achieve financial strength in the spouse, for instance, limiting female spouse's funds accessibility and diminishing the capability to gain job opportunity or further education (Sanders, 2011).

Looking at the previous review, the researchers of the present study strongly believe that the sensitivity of financial issues and its connection with spousal violence, create the need to agitate for inclusion of increase financial burden or economic deprivation as a sub-component of spousal violence. More importantly, scholars have emphasized that, to help victims and survivors of spousal abuse, efforts should be made to enhance their financial strength and palliative measures of similar approach be provided by the non-governmental and government agencies for safety of these individuals (Aina, 2004; Sanders, 2011). Intimate partners' relationship are one of those most salient factors that could impact mental health. Therefore, there is dire need for a study like this. The following research hypotheses were postulated in the course of this research:

1 Participants' gender will have a significant influence on spousal violence during COVID-19 pandemic lockdown

2 Socioeconomic status will have a significant influence on spousal violence during COVID-19 pandemic lockdown

3 Job status, religion affiliation, tribe and living condition will have significant influence on spousal violence during COVID-19 pandemic lockdown 


\section{Methods}

\section{Design}

This study used a web-based cross-sectional survey study which was conducted via social media (Facebook and WhatsApp groups) using google form from March 3 to April 4, 2020.

\section{Setting}

The data collected for this study were limited to the married residents in Kwara State, Nigeria. This state is composed of sixteen local governments and three federal senatorial districts. The state is located at the NorthCentral parts of Nigeria. Residents in this state are from different ethnic groups across Nigeria. The area is considered suitable for this kind of research as it is convenient for the researchers to locate the potential respondents through snowballing from respondents to another because of the movement restriction during the study.

\section{Participants}

Respondents in this study were three hundred and fifty-six (356) adults who were either in relationship, cohabiting, married or recently separated, and were aged between 18 years and 68 years. It was observed that there were $141(39.61 \%)$ male respondents and $215(60.39 \%)$ female respondents (whose age ranged between 18 to 68 years). Also, $286(80.3 \%)$ were married, 60 (16.9\%) were cohabiting while 10 (2.8\%) were divorcees/separated individuals. In terms of religion, 147 (41.3\%) were Christians and 154 (43.3\%) were Muslims while the traditionalists/other religions were 55 (15.4\%). Regarding their educational qualifications, $50(14.0 \%)$ had basic education, 80 (22.5\%) had Secondary School certificate, $88(24.7 \%)$ had diploma and its equivalents, $100(28.1 \%)$ had bachelor degree and its equivalents, while 38 (10.7\%) had Masters and above. Also, 176 (49.4\%) were operating nuclear type of family while 180 (50.6\%) were from extended family (see table 1$)$.

\section{Ethical considerations}

Human research survey required informed consent according to local legislation and institution ethical rules. For the current study, the participants read and signed the informed consent by clicking the "I accept to participate" button on the online google form. Strict adherence to ethical provisions on free participation and exit, willingness to participate, confidentiality and autonomy were also observed.

\section{Sampling procedure}

The participants were recruited through a snowball sampling technique via social media posts to complete the online survey using Google forms website. Participants indicated their consent to participate in the study by clicking the "next" button after reading the informed consent. Inclusion criteria for the study were ability to read and write in English, participants consent to participate, adults who were either in relationship, cohabiting, married or recently separated, and were aged between 18 to 68 years. It was designed in a way that nobody can fill more than one questionnaire in the survey study. Those who were willing to participate in this study were asked to click on the informed consent form attached to the questionnaire as a sign of willingness to participate. Data were collected and analyse after a month interval of administering the questionnaire.

\section{Instruments}

The online self-reported questionnaire contained respondents' demographic information such as; gender, age, religion affiliation, job status, income, living condition, location etc. And the Composite Abuse Scale (Revised)Short Form $\left(\mathrm{CAS}_{\mathrm{R}}-\mathrm{SF}\right)$ designed by Ford-Gilboe et al., (2016). The details are discussed thus:

\section{The composite abuse scale (Revised)—Short form $\left(C A S_{R}-S F\right)$}

The $\mathrm{CAS}_{\mathrm{R}} \mathrm{SF}$ was adapted for use during this study to measure intimate partner or spousal violence experience in individual. Statement like, "Within a month or less, did you experience ......" were added to the items for it to suit the purpose of the study at the pandemic lockdown. The response format involves; not at all=0, 'once' $=1$, 'a few times'=2, 'monthly'=3, 'weekly'=4, and 'daily or almost daily=5. A 15 -item version of the CAS has been 


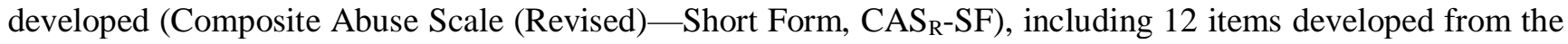
original CAS and 3 items suggested through expert consultation and the evolving literature. Items cover 3 abuse domains: physical, sexual and psychological, with questions asked to assess lifetime, recent and current exposure, and abuse frequency. Factor loadings for the final 3-factor solution ranged from 0.81 to 0.91 for the 6 psychological abuse items, 0.63 to 0.92 for the 4 physical abuse items, and 0.85 and 0.93 for the 2 sexual abuse items. Moderate correlations were observed between the $\mathrm{CAS}_{\mathrm{R}}-\mathrm{SF}$ and measures of depression, post-traumatic stress disorder and coercive control. Internal consistency of the $\mathrm{CAS}_{\mathrm{R}} \mathrm{SF}$ was 0.942. Cronbach's $\alpha$ was 0.975. The internal consistency of each subscale was acceptable (0.938 for psychological abuse, 0.847 for physical abuse, 0.884 for sexual abuse). The scale is scored by adding all response together; scores range from 0-75; below 30 is low, 31 to 45 is moderate while above 45 is high. The present study recorded reliability of Cronbach's alpha of .77.

\section{Statistical analysis of data}

Data was analyzed using (statistical packages for the social sciences) SPSS 21.0. Descriptive statistics such as frequency, mean, Standard Deviation and variance were performed to describe the participants' information. The reliability analysis of the study instruments was ascertained and reported as local reliability for future reference. Hypotheses 1, 2 and 3 were analyzed using mean difference statistics.

\section{Results}

The results cover the descriptive analyses of demographic information of the participants and the inferential statistics that test for the significance of the research hypotheses formulated in the present study.

\section{Descriptive analysis}

The summary of the descriptive analyses for the demographic distribution of the participants are presented in Table 1 as follows:

Table 1: Summary Showing Descriptive Analysis of the Demographic Factors

\begin{tabular}{lll}
\hline Variables & Frequency & Percentage \\
\hline Gender & 141 & 39.61 \\
Male & 215 & 60.39 \\
Female & 356 & 100.0 \\
Total & & \\
Marital Status & 286 & 80.3 \\
Married & 10 & 2.8 \\
Divorced/separated & 60 & 61.9 \\
Living with partner but yet to be wedded & 356 & 100.0 \\
Total & & \\
Religion & 147 & 41.3 \\
Christianity & 154 & 43.3 \\
Islam & 55 & 15.4 \\
Traditionalists & 356 & 100.0 \\
Total & & \\
Education & 50 & 14.0 \\
Basic education & 80 & 22.3 \\
SSCE & 88 & 24.2 \\
OND/NCE & 100 & 28.1 \\
BSc/HND & 38 & 10.7 \\
Masters and above & 356 & 100.0 \\
Total & & \\
Family Type & 176 & 49.4 \\
Nuclear & 180 & 50.6 \\
Extended & 356 & 100.0 \\
Total & &
\end{tabular}




\footnotetext{
Age range (18 to 66 years of age)

Source: Authors' field data computation (2020)
}

From the descriptive result, it was observed that participants who were traditionally and legally married were the majority, followed by partners who were cohabiting. In terms of religion, Muslims have the highest numbers of respondents followed by Christians while the traditionalists/other religion had the lowest responses. Regarding their educational qualifications; those with OND/NCE participated more, followed by those with secondary school qualifications while those with postgraduate qualifications had the least number of participants. At family levels, participants that operate extended type of family were the majority followed by those who operate nuclear family.

\section{Test of research hypotheses}

Recall that hypothesis one, which states that participants' gender will significantly influence spousal violence during COVID-19 pandemic lockdown. In in the Table 2 presented in this study, the findings showed that there is no significant difference of gender on spousal violence $[\mathrm{F}=.05, \mathrm{p}>.05]$. That is, both gender (males and females) experience spousal violence in the same manner and no one experienced higher than another. Therefore, the hypothesis is rejected for this factor (see the result in Table 2).

For the second hypothesis which states that socioeconomic status will have significant influence on spousal violence during COVID-19 pandemic lockdown was presented table 2. The result revealed that the income of participants significantly influenced spousal violence $[\mathrm{F}=4.911, \mathrm{p}<.01]$. Furthermore, those who earned below 20,000 thousand naira per month reported high spousal violence $(M=14.50)$ compare with others who earned between 20,000 to 50,000 naira per month $(\mathrm{M}=13.49)$ and couples earning 51,000 thousand naira and above (M $=13.44$ ). This showed that the lower the income the more the incidents of spousal violence during coronavirus lockdown (see the result in Table 2). Therefore, the hypothesis is accepted for this factor.

For the third hypothesis which states that job status, religion affiliation, tribal affiliation and living condition will have significant influence on spousal violence during COVID-19 pandemic lockdown was presented below. The findings showed some significant differences in the living conditions of couples on spousal violence [ $\mathrm{F}=2.91$, $\mathrm{p}<.05]$ and job status of the participants $[\mathrm{F}=4.912, \mathrm{p}<.01]$. However, there is no significant difference on spousal violence when considering; religion affiliation $[\mathrm{F}=1.80, \mathrm{p}>.05]$, type of family $[\mathrm{F}=1.23, \mathrm{p}>.05]$, and tribal affiliation $[\mathrm{F}=1.61, \mathrm{p}>.05]$, therefore, this hypothesis is rejected for these factors. However, the hypothesis is accepted for living condition of couples and their job status (see the result in Table 2).

Furthermore, those living in rented apartment with third party (that is; living with relatives either from husband or wife family as well as friends from both party) scored high significantly on spousal violence $(\mathrm{M}=14.70)$ compare with others living in owned house with third party $(\mathrm{M}=12.22)$ and those living in rented apartment with no third party $(\mathrm{M}=13.33)$.

Also considering the results of the current study the means score of job status of participants differs as those engaged with government job (public job) score lower $(M=13.10)$ follow by those working with private firms (private job) who have means of $(\mathrm{M}=13.99)$ and those with their own small scale business and artisans, traders had highest degree means of $(M=14.55)$ on spousal violence; these results shows that those who have job security scored lower on spousal violence during the pandemic lockdown in kwara state, compare with those who were self-employed, petty traders, artisans and or are working with private firms or establishments in Kwara State (Nigeria), (see Table 2). 
Table 2, Summary Showing Significant Mean Differences of Spousal Violence in SocioDemographic Factors (Dependent variable: Spousal Violence)

\begin{tabular}{|c|c|c|c|c|}
\hline Variables & Mean & SD & F & $\mathrm{P}$ \\
\hline \multicolumn{5}{|l|}{ Gender } \\
\hline Male & 14.20 & 1.87 & .048 & $>.05$ \\
\hline Female & 14.14 & 2.08 & & \\
\hline \multicolumn{5}{|l|}{ Living Condition } \\
\hline Living in Own House with Third Party & 12.22 & 1.780 & & \\
\hline Living in Rented Apartment with Third Party & 14.70 & 2.406 & $2.911 *$ & $<.05$ \\
\hline Living in Rented Apartment with no Third Party & 13.33 & 1.982 & & \\
\hline \multicolumn{5}{|l|}{ Religion } \\
\hline Christianity & 13.99 & 2.041 & & \\
\hline Islam & 14.49 & 1.694 & 1.80 & $>.05$ \\
\hline Others & 13.50 & 2.121 & & \\
\hline \multicolumn{5}{|l|}{ Type of Family } \\
\hline Nuclear & 14.30 & 2.066 & 1.23 & $>.05$ \\
\hline Extended & 13.93 & 1.403 & & \\
\hline \multicolumn{5}{|l|}{ Tribe of the Spouse } \\
\hline Intra-tribe & 13.38 & 1.778 & 1.61 & $>.05$ \\
\hline Inter-tribe & 13.97 & 2.337 & & \\
\hline \multicolumn{5}{|l|}{ Types of Job/Employment } \\
\hline Public Job & 13.10 & 1.732 & & \\
\hline Private Job & 13.99 & 1.935 & $4.912 * *$ & $<.01$ \\
\hline Small Scale Business/Artisan/Trader & 14.55 & 2.164 & & \\
\hline Income ( & 14.50 & 2.932 & & \\
\hline Below 20,000 & 13.49 & 1.735 & $4.913 * *$ & $<.01$ \\
\hline $20,000-50,000$ & 13.44 & 1.626 & & \\
\hline 51,000 and above & & & & \\
\hline
\end{tabular}

Source: Authors' field data computation (2020)

\section{Discussion}

Findings from the study tend to support what many other similar studies have found, though there are some contradictions. The first hypothesis which states that there will be a significant difference of gender on spousal violence during COVID-19 pandemic lockdown. The findings showed that there is no significant difference of gender on spousal violence. That is, both gender (males and females) experience spousal violence in the same manner. This result is similar a previous study (Oguntayo et al., 2018); although, this study was not conducted during COVID-19 lockdown. However, the present study contradicted the findings of Jang (2020), which found that many women suffered domestic violence during COVID-19 lockdown in China. looking at this contradiction in findings, there is need for more research on gender difference regarding spousal violence during COVID-19 lockdown.

For the second hypothesis which states that socioeconomic status will have significant influence on spousal violence during COVID-19 pandemic lockdown. The result revealed that the income of the participants significantly influenced spousal violence. Studies have showed that income status of a spouse could serve as a protective factor for them to endure spousal violence (Oguntayo et al., 2018; Iman'ishimwe, Machakanja, \& Adjei, 2020; Department for International Development's country office in Nigeria (DFID), 2020). This study is suggesting that economic distress is a serious predisposing factor to spousal violence especially during emergency 
like the present pandemic. By implication, there is need to consider partner's income levels when considering the causes of SV. During COVID-19 lockdown, many business activities were obstructed and some owners of business were restricted from transacting without adequate compensation or palliative measures (DFID, 2020). Meanwhile, Nigeria is a country where the small-scale business owners make up to $65 \%$ of the country Gross Domestic Products (Bank of Industry, 2017), with a clear proportion of the residents relying solely on daily profits for survival. The reduction in the income rate of the residents may have resulted in the escalation of domestic violence among the residents. The study is a suggestive that, there exists an interplay between income of partners and spousal violence. Furthermore, financial constraint of spouse has tendency to trigger spousal violence considering the previous literature explored in this study.

For the third hypothesis which states that job status, religion affiliation, tribe of one's spouse and types of living condition will have significant difference on spousal violence during COVID-19 pandemic lockdown. The findings showed some significant differences in the living conditions of couples on spousal violence, and job status of the participants. A study has opined that unstable living condition exacerbate spousal violence (Jang, 2020). These results showed that those who have job security (government workers) scored the lowest means on domestic violence followed by the private companies' employees while those whom their income might have been obstructed (self-employed, traders, artisans, unemployed etc) did have higher scores on spousal violence during COVID-19 pandemic lockdown in kwara state, Nigeria. The inadequate income and the dwindling economy of the country might have aroused the spouses' aggression and helplessness which result in the high discordant relationship in studied area. Those living in rented apartments with third party might have witnessed financial constraints, which have tendency to trigger dyadic relationship outcomes as witnessed by the sampled participants. Several studies have found similar results that unemployment, living standard, financial difficulty and third-party intrusion did trigger domestic violence or marital conflict especially in sub-Saharan Africa. Although unlike the findings of Oguntayo et al. (2020), those studies were not conducted during disease outbreak or lockdown like it was in this study (Bamiwuye, \& Odimegwu, 2014; DFID, 2020; Okhakhume, et al., 2016).

\section{Conclusion and Recommendations}

This study examined how contextual factors, demographics and economic distress interplay with spousal violence during COVID-19 lockdown. Three hypotheses were formulated thus; participants' gender will have a significantly influence on spousal violence during COVID-19 pandemic lockdown, socioeconomic status will have a significant influence on spousal violence during COVID-19 pandemic lockdown, and job status, religion affiliation, tribe and living condition will have significant influence on spousal violence during COVID-19 pandemic lockdown. The results showed that gender does not differ on spousal violence. However, the income of the participants significantly influenced spousal violence. So also, there were significant influences of job status and living conditions on spousal violence among the selected spouse during coronavirus pandemic lockdown in Kwara state, Nigeria. However, there was no significant influence of religion affiliation, types of family and tribe of the sampled participants on spousal violence. Considering the previous reviews and the results obtained in the current research, it is strongly recommended that financial deprivation by partner otherwise referred to as economic spousal violence be added as one of the sub-components of the spousal violence. This is because, the spousal violence and economic distress (financial constraints and related factor like standard of living and job status) have been found to be related with spousal violence which is agreement with previous studies aforementioned in this study (e. g., Gjertson, 2011; Okhakume et al.,2016; Oguntayo et al., 2018; Oguntayo et al., 2020; Pappas, 2020). Moreover, on the basis of the findings reached in this study, the following measures are suggested in order to reduce the phenomenon of spousal violence both at the present pandemic and the future lockdown:

I. There is a need for experts in mental health and economic sectors to form a synergy where policy formulation, community services and media awareness/campaign could be championed by both 
professionals on immediate measures to overcome economic distress in order to contain the surging level of spousal violence in the society both at the present pandemic and in the future.

II. Palliative measures for business owners or self-employed individuals who have tendency to be financially burdened or economically distressed during lockdown or crisis should be objectively discharged so that the vulnerable will be reached out to.

III. Government should formulate policy that will discourage retrenchment of private employees during emergency or crisis to forestall poor standard of living among families in the society to reduce spousal violence.

\section{Limitation of the study}

This study utilized relatively small numbers of participants and apparently the literate ones, as a result, the findings of this study should be carefully generalized as there is a likelihood that if more respondents especially the illiterate were to be involved, the outcomes would change. Finally, response bias in this type of survey maybe difficult to rule out which most times limit people's opinion; a study like this may have a shortcoming considering these factors.

\section{References}

Aina O. I. (2004). Domestic violence among Yoruba middle class. In: I. M. Thomas, L Erinosho, F Orenuga (Eds.): Domestic violence among middle class Nigerians. Lagos: Inter-African Committee, pp. 6-33.

Bamiwuye, S.O., \& Odimegwu, C. (2014), Spousal violence in sub-Saharan Africa: does household povertywealth matter? Reproductive Health,11, 45. doi: 10.1186/1742-4755-11-45. PMC:40765

Bank of Industry. (2017). Economic development through the Nigerian informal sector: A BOI Perspective. Retrieved from: https://www.boi.ng/wp-content/uploads/2018/05/BOI-Working-Paper-SeriesNo2_Economic-Development-through-the-Nigerian-Informal-Sector-A-BOI-perspective.pdf

Baker-Tingey, J. (2020). COVID-19 contributing to domestic violence: what to do. Retrieved From: https://www.unr.edu/nevada-today/news/2020/covid-and-domestic-violence

Bettinger-Lopez, C., \& Bro, A. (2020). A double pandemic: Domestic violence in the age of COVID-19. Council of foreign relations forum. Retrieved from: https://www.cfr.org/in-brief/double-double pandemic-domestic-violence-age -covid-19

Centers for Disease Control and Prevention. (n.d). Survey. Retrieved from https://edition.cnn.com/2011/12/15/health/violence-survey/index.html

Domestic Sexual and Violence Response Team. (2020). Increase in domestic violence amid COVID-19 Pandemic is dangerous to the victims and society. Retrieved from http://dsvrtlagos.org/

Department for International Development's country office in Nigeria (DFID). (2020). Impact of COVID-19 pandemic on violence against women and girls. Retrieved from; https://reliefweb.int/sites/reliefweb.int/files/resources/VAWG-Evidence-Digest-April20_0.pdf

Ford-Gilboe, M., Wathen, C.N., Varcoe, C., MacMillan, H.L., Scott-Storey, K., Mantler, T., Hegarty, K. \& Perrin, N. (2016). Development of a brief measure of intimate partner violence experiences: The composite abuse scale (Revised)-Short Form $\left(\mathrm{CAS}_{\mathrm{R}}-\mathrm{SF}\right)$. BMJ Open, 6(12), 12-24. Retrieved from: https://doi.org/10.1136/bmjopen-2016-012824

Gjertson, L. M. (2011). Summary of workshop proceedings: Exploring the Intersection between Financial Capability and Domestic Violence. (CFS Issue Brief 2011-5.7). Center for Financial Security, University of Wisconsin-Madison

Iman'ishimwe, M., J., Machakanja, P., \& Adjei, N.K. (2020). Trends in prevalence and correlates of intimate partner violence against women in Zimbabwe, 2005-2015. BMC Int Health Hum Rights, 20(2). https://doi.org/10.1186/s12914-019-0220-8

Jang, B. (2020). Gender based violence during the COVID-19 pandemic and economic, social and cultural rights. Retrieved from: http://opiniojuris.org/2020/04/23/gender-based-violence-during-the-covid-19pandemic-and-economic-social-and-cultural-rights/ 
Kishor, S. (2012). Married women's risk of STIs in developing countries: the role of intimate partner violence and partner's infection status. Violence Against Women 18 (7), 829-53.

Motevaliyan, S.M., Yaacob, S. N., Juhari, R., Mansor, M., \& Baratvand, M. (2014). Personality traits and severity of wife abuse among Iranian women. Asian Social Science, 10(7), 234-241. doi:10.5539/ass.v10n7p234

Okhakhume, A.S., Oguntayo, R., \& Aroniyiaso, O.T. (2016). Influence of socio-economic status and marital satisfaction on domestic violence among couples living in Nigeria. International Journal of Applied Psychology, 6, 179-84.

Oguntayo, R. (2016). The influence of personality, emotional intelligence and marital satisfaction on domestic violence among couples in Ibadan metropolis. University of Ibadan, Msc dissertation. Retrieved from: https://afribary.com/works/domestic-violencepdf

Oguntayo, R., Opayemi, A.S., Oyeleke, J.O., \& Popoola, O.A. (2018). Influence of socio-economic status on domestic violence among couples in Ibadan Metropolis. Journal of Psychological Science, 3(1):14-25. Available online at http://journals. aphriapub.com/index.php/EJPS

Oguntayo, R., Oyeleke, J., John-Oguntayo, O., \& Aajayi-Hutchful, F. (2020). Personality traits, emotional intelligence, socio-contextual factors and spousal violence: The trajectory of COVID-19 pandemic lockdown. International Journal of Behavioral Sciences, 14(2), 101-107. doi: $10.30491 /$ ijbs.2020.232959.1290

Olatunji, K. (2020). There is increase in sexual, domestic violence reports despite lockdown, says DSVRT. Retrieved From https://guardian.ng/news/nigeria/there-is-increase-in-sexual-domesticviolence-reports-despite-lockdown-says-dsvrt/

Pappas, S. (2020, April 6). How will people react to the new financial crisis? American Psychological Association. https://www.apa.org/news/apa/2020/04/financial-crisis-covid-19

Sanders, C. K. (2011). Asset building programs for domestic violence survivors. National Online Resource Center on Violence against Women.

United Nation. (2002). Addressing trauma caused by violence against women. Retrieved from:www.unoviolence.org/../GBVGuide08 english.pdf.

UNFPA. (2020). Impact of the COVID-19 pandemic on family planning and ending gender-based violence, female genital mutilation and child marriage. Interim Technical Note. Retrieved from:

UN Women. (2020). Violence against women and girls: The shadow pandemic. Retrieved from: https://www.unwomen.org/en/news/ stories/2020/4/statement-ed-phumzile-violence-against-womenduring-pandemic

UNICEF. (2000). Domestic violence against women and girls. Innocenti Digest, 6

USAID, (2002). Addressing gender based violence against women. Retrieved from http://www.prb.org/../GBVGuide08_english.pdf.

$\begin{array}{llllll}\text { Worldometer. } & \text { (2020) COVID-19 } & \text { coronavirus } & \text { pandemic. } & \text { Available from }\end{array}$ https://www.worldometers.info/coronavirus/

World Health Organisation, (2017). Violence against women. Retrieved from https://unstats.un.org/unsd/gender/downloads/WorldsWomen2015_chapter6_t.pdf

World Health Organisation, (2014). Intimate partner violence. Retrieved from http://www.who.int/violence_injury_prevention/violence/world_report/factsheets01/09/2015. 